\title{
Impacts of the Primary School Free Breakfast Initiative on socio-economic inequalities in breakfast consumption among 9-11-year-old schoolchildren in Wales
}

\author{
Graham F Moore ${ }^{1, *}$, Simon Murphy ${ }^{1}$, Katherine Chaplin ${ }^{2}$, Ronan A Lyons ${ }^{3}$, \\ Mark Atkinson ${ }^{3}$ and Laurence Moore ${ }^{1}$ \\ 'DECIPHer, School of Social Sciences, Cardiff University, 1-3 Museum Place, Cardiff CF10 3BD, UK: ${ }^{2}$ School of \\ Social and Community Medicine, University of Bristol, Bristol, UK: ${ }^{3}$ Health Information Research Unit, College of \\ Medicine, Swansea University, Swansea, UK
}

Submitted 30 January 2013: Final revision received 3 October 2013: Accepted 21 October 2013: First published online 3 December 2013

\begin{abstract}
Objectives: Universal interventions may widen or narrow inequalities if disproportionately effective among higher or lower socio-economic groups. The present paper examines impacts of the Primary School Free Breakfast Initiative in Wales on inequalities in children's dietary behaviours and cognitive functioning. Design: Cluster-randomised controlled trial. Responses were linked to free school meal (FSM) entitlement via the Secure Anonymised Information Linkage databank. Impacts on inequalities were evaluated using weighted school-level regression models with interaction terms for intervention $\times$ whole-school percentage FSM entitlement and intervention $\times$ aggregated individual FSM entitlement. Individual-level regression models included interaction terms for intervention $x$ individual FSM entitlement.

Setting: Fifty-five intervention and fifty-six wait-list control primary schools.

Subjects: Approximately 4500 children completed measures of dietary behaviours and cognitive tests at baseline and 12-month follow-up.

Results: School-level models indicated that children in intervention schools ate a greater number of healthy items for breakfast than children in control schools $(b=0 \cdot 25 ; 95 \%$ CI $0 \cdot 07,0 \cdot 44)$, with larger increases observed in more deprived schools (interaction term $b=1 \cdot 76 ; 95 \%$ CI $0 \cdot 36,3 \cdot 16$ ). An interaction between intervention and household-level deprivation was not significant. Despite no main effects on breakfast skipping, a significant interaction was observed, indicating declines in breakfast skipping in more deprived schools (interaction term $b=-0 \cdot 07 ; 95 \% \mathrm{CI}-0 \cdot 15,-0 \cdot 00)$ and households (OR $=0 \cdot 67 ; 95 \% \mathrm{CI} 0 \cdot 46$, $0 \cdot 98)$. No significant influence on inequality was observed for the remaining outcomes.

Conclusions: Universal breakfast provision may reduce socio-economic inequalities in consumption of healthy breakfast items and breakfast skipping. There was no evidence of intervention-generated inequalities in any outcomes.
\end{abstract}

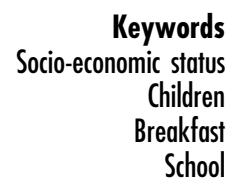

In the UK, health outcomes and life expectancy improve substantially with increased socio-economic status (SES) ${ }^{(1)}$. Inequalities cannot be entirely attributed to behaviours such as diet and smoking, also arising from structural factors such as housing and employment security ${ }^{(2)}$. However, more healthful behaviours are typically observed among higher-SES individuals ${ }^{(3,4)}$. Socio-economic discrepancies in many health behaviours emerge in childhood ${ }^{(5)}$. Hence, interventions to improve childhood health behaviours, increasingly delivered through schools $^{(6)}$, may play a significant role in reducing inequalities.
One potential behavioural contributor to health inequalities, commonly targeted by school-based interventions, is breakfast consumption. Skipping breakfast is associated with a variety of detrimental outcomes, including dental caries ${ }^{(7)}$, dysmenorrhoea ${ }^{(8)}$ and reduced weight control ${ }^{(9)}$, while breakfast contributes significantly to the overall nutritional adequacy of children's diets ${ }^{(10-12)}$. Consumption of breakfast has also been associated with improved cognitive performance ${ }^{(13-17)}$, with potential implications for educational attainment. However, many children do not eat adequate breakfasts ${ }^{(18,19)}$, while

*Corresponding author: Email MooreG@cardiff.ac.uk

(C) The Authors 2013. The online version of this article is published within an Open Access environment subject to the conditions of the Creative Commons Attribution licence http://creativecommons.org/licenses/by/3.0/. 
breakfast skipping and consumption of lower-quality breakfasts are more common among children from lowerSES families ${ }^{(20)}$.

Possibly the most common school-based intervention for promoting healthful breakfast consumption is through 'breakfast clubs'. These were first adopted in North America in the 1960s with the aim of improving the nutritional status of children in more deprived areas ${ }^{(21)}$. By 1997 approximately six million children in the USA were attending a school breakfast club each day ${ }^{(22)}$. In the UK, their introduction has occurred more recently. By 2012 however, breakfast clubs were available in almost half of schools in England, with delivery concentrated in areas of deprivation ${ }^{(19)}$. In Wales, the Welsh Government's Primary School Free Breakfast Initiative (PSFBI) was implemented from $2005^{(23)}$, offering all primary schools resources and guidance to provide free, healthy breakfasts before the start of the school day. An estimated three-quarters of primary schools throughout Wales have taken up this scheme to date ${ }^{(24)}$. While there is some evidence that school breakfast programmes can help improve nutrition and may lead to improvements in attendance, academic performance and behaviour ${ }^{(25-29)}$, findings have been inconsistent ${ }^{(21)}$ with robust evaluation hampered by difficulties such as contamination between trial arms ${ }^{(30)}$. Furthermore, the aims of breakfast clubs, and hence the outcomes measured by their evaluations, have diverged considerably, with some focusing on provision of a healthy breakfast while others emphasise child care, education or informal interaction between children and school staff ${ }^{(31)}$. One trial from the USA ${ }^{(32)}$ for example provides robust evidence that universal breakfast provision can improve pupil nutrition, although a recent trial in deprived areas in New Zealand emphasised school attendance and educational attainment as primary goals, finding no impact on these outcomes ${ }^{(33)}$.

As described above, breakfast clubs originated as a means of reducing inequality through improving the nutritional status of children in more deprived areas and, with some notable exceptions ${ }^{(32)}$, evaluations have typically focused on targeted provision ${ }^{(30,33)}$. However, while targeting resources towards schools in areas of deprivation is intuitively appealing, targeted approaches may not always be the most effective means of reducing inequality. Targeting may stigmatise individuals, schools, families or communities through labelling them as needy; widely recognised as a barrier to the uptake of free school meals (FSM) among many children from poorer families ${ }^{(34)}$. In addition, given that relationships between SES and health outcomes are typically graded rather than dichotomous, targeting the very poorest will do little to address inequalities throughout the distribution ${ }^{(1)}$.

For these reasons, attention is increasingly turning to the need to identify universal interventions whose impacts are proportionately greater further down the socio-economic distribution ${ }^{(1)}$. Of course, universal interventions may also have the opposite effect, widening inequality through disproportionately benefiting more affluent groups. Hence, Whitehead ${ }^{(35)}$ has called for all evaluations of health improvement interventions to evaluate impacts on inequality, regardless of whether their explicit aim is to reduce inequality or to improve population-level health, in order to build an evidencebased typology of actions which reduce or worsen inequality. At present, there is tentative evidence that actions based on education, information provision and promotion of voluntary change are more likely to generate inequality, while altering higher-level factors to make healthy behaviours easier may be more likely to reduce inequalities ${ }^{(35-38)}$. Breakfast provision represents an attempt to improve behaviour through altering the environment to improve the availability of healthy breakfasts, therefore making the behaviour easier. Hence, one would perhaps expect it to be more likely to narrow inequality than approaches such as educating children about the benefits of breakfast while the option of eating a healthy breakfast continues to be unavailable for some. No studies to date have examined differential effectiveness of universal breakfast provision by SES.

The current paper presents secondary analysis of data from the cluster-randomised controlled trial of the PSFBI in Wales and aims to understand its role in reducing inequalities in children's consumption of breakfast. The PSFBI formed a Welsh Labour Party manifesto commitment to offer Welsh primary schools guidance and resources to offer free healthy breakfasts to all children. Although schools in areas of deprivation were targeted in the initial phases of implementation, it was ultimately made available to all schools. At the aggregate level, trial data published in this journal indicate that while PSFBI had no impact on breakfast skipping, with children substituting breakfast at home for a breakfast at school ${ }^{(39)}$, the shift from home-based to school-based consumption appeared to significantly improve the healthfulness of items consumed for breakfast, also leading to more positive attitudes towards breakfast.

Analysis of baseline data, also published in this journal, indicated that children attending more deprived schools ate poorer-quality breakfasts than their higher-SES counterparts and had less positive attitudes towards breakfast than did children from more affluent schools ${ }^{(20)}$. Hence, while there was no overall impact on breakfast skipping, given that children from more deprived backgrounds were eating poorer-quality breakfasts at home prior to intervention, the move from eating breakfast in the home towards eating healthy breakfasts in school may have disproportionately improved dietary quality among children from more deprived backgrounds. The present paper examines impacts of PSFBI on socio-economic gradients in dietary behaviours and cognitive performance, in order to evaluate the potential impact of universal breakfast provision on inequalities in health and educational attainment. 


\section{Method}

\section{The Primary School Free Breakfast Initiative}

The intervention provided a school-based breakfast before the commencement of classes, without any cost being borne by parents. The aim of the intervention was not only to encourage breakfast consumption per se, but also to improve the nutritional quality of children's breakfasts. Hence a particular focus was placed upon limiting available food choices to breakfast items considered to be healthful. Breakfasts provided included items from four food types: non-sugar coated cereals, bread, milk products and fruits, in addition to drinks. Schools were provided with guidelines regarding how the scheme should be run, in terms of staff to student ratios and the food to be provided, but were given a reasonable degree of autonomy in the operation of the scheme. At the time of writing, information about the scheme can be found on the Welsh Assembly Government's website ${ }^{(40)}$.

\section{Participants}

Primary schools located in Wales were approached to take part in a cluster-randomised controlled trial of the Welsh Government's PSFBI. A total of 111 schools took part, of which fifty-eight were 'Communities First' schools (located in socio-economically deprived areas). Participants were Year 5 and 6 students (i.e. aged 9-11 years) within these 111 schools. One Year 5 and one Year 6 class from each school was selected to complete the attitudes and dietary recall questionnaires. A total of 4350 students at baseline and 4472 at 12-month follow-up completed the classroom-based measures within all 111 schools. The fact that a higher number of children participated at follow-up is a consequence of the fact that the study involved repeated cross-sections in the same schools at baseline and 12-month follow-up. Due to increased class sizes in some schools, the eligible pool of children increased slightly, although response rates were identical at baseline and follow-up (88.3\%). Teacher-completed behavioural questionnaires were completed in relation to $1034 / 947$ children within 105/99 schools at baseline/ follow-up. Of the 4472 children who completed followup measures, individual-level FSM entitlement data were obtained for $3068(68 \cdot 6 \%)$.

\section{Measures}

\section{Deprivation}

This was assessed using data on FSM entitlement. Two variables were used for school-level analyses: (i) the percentage of all children within the school entitled to FSM (provided by the Welsh Government) and (ii) the percentage of study participants within each school entitled to FSM at Key Stage 2 (aged 7-11 years; data obtained from the Secure Anonymised Information Linkage (SAIL) databank). For individual-level analysis, children's own entitlement to FSM (yes or no) was used as a binary indicator of deprivation.

\section{Attitudes towards eating breakfast}

Attitudes were assessed by asking pupils to indicate agreement with thirteen statements on a scale of 1 (strongly agree) to 5 (strongly disagree). Items referred to a variety of domains, such as concentration and behaviour, energy, and the general importance placed on breakfast. The measure has demonstrated good construct and convergent validity using baseline data used in the present study ${ }^{(41)}$.

\section{Dietary recall questionnaire}

The questionnaire was a modified version of the Day in the Life Questionnaire ${ }^{(42)}$. This measure has been validated against $24 \mathrm{~h}$ recall interviews with a sub-sample of children from the present study and offers an acceptable level of validity and reliability ${ }^{(43)}$. In fact, the measure covered a period slightly in excess of $24 \mathrm{~h}$; children were asked to list all foods and drinks consumed at chronologically ordered time points throughout the previous day and for breakfast on the day of reporting. Outcome variables are the proportion of children consuming less than two breakfasts over $2 \mathrm{~d}$, the number of healthy items (i.e. cereals, bread, fruits and milk products) consumed for breakfast, the number of unhealthy items consumed for breakfast (i.e. crisps and sweet snacks), the number of fruit and vegetables consumed during the rest of the day and the number of unhealthy items (i.e. crisps and sweet snacks) consumed during the rest of the day.

\section{Classroom cognitive tests}

Classroom-level measures were pen-and-paper tests which had previously been shown to be sensitive to the effects of breakfast in experimental studies ${ }^{(44,45)}$. These included: a word recall test of episodic memory ${ }^{(44)}$; a backward letter span test of working memory, similar in nature to the backward digit span test ${ }^{(46)}$; and two search and memory task (single \& five letter) tests ${ }^{(46)}$ of discrimination, sustained attention and psychomotor speed. Episodic memory was identified as the primary cognitive outcome in the published protocol, so analysis focuses on this measure.

\section{Behavioural problems}

The Strengths and Difficulties Questionnaire (SDQ) ${ }^{(47)}$ provides measures of behavioural difficulties in four domains: (i) conduct problems, (ii) emotional problems, (iii) hyperactivity and (iv) peer problems; as well as strengths in terms of pro-social behaviour. The SDQ was completed by teachers to assess the classroom behaviour of a randomly selected sub-sample of five of their students in each year group (i.e. ten students in total for each school). Hyperactivity was identified as a key secondary outcome in the published protocol, so analysis focuses on this subscale. 


\section{Procedure}

For the original trial, parents were informed of the research by means of a letter and information sheet sent home with children and were asked to contact the school if they did not wish their child to participate in the study. Parents of fifteen children requested that their child be excluded. At each data collection, children were also informed that they were under no obligation to participate. The present study received ethical approval from the Cardiff University Social Science Ethics Committee.

Class-level measures were completed in the morning (between 09.00 and 11.00 hours) as a supervised classroom exercise with a maximum class size of forty children. For the attitudes questionnaire, the researcher read statements one by one and children marked their response for each statement after it was read out, to minimise conferring and ensure that children did not distract one another. For the dietary recall measure and the cognitive measures, the researcher read out the instructions and asked children to complete the task independently from one another. If children had finished or needed help with spelling or further clarification, they were asked to put their hand up. Three members of the research team were present to assist children.

The SAIL databank is a data warehouse which was established at the Health Information Research Unit (HIRU) at the College of Medicine at Swansea University. It brings together a wide range of person-based data, using a splitfile approach to anonymisation to overcome issues of confidentiality and disclosure ${ }^{(48)}$, and operates within a robust series of guidelines in line with the Caldicott principles and the National Information Governance Board for Health and Social Care ${ }^{(49)}$. Participating children were each assigned an Anonymised Linking Field (ALF_E) ${ }^{(48)}$ and thereby linked to the National Pupil Database for Wales, a version of which is held on the SAIL databank.

\section{Statistical analysis}

For each variable, school-level mean scores were calculated by summing scores for each child and dividing the total by the number of children within the school. That is, data from the 4350 children at baseline and 4472 at follow-up for measures collected within the whole class were aggregated at the school level (approximately forty children per school at each time point). For the sub-sample of children for whom the behavioural questionnaire was completed, data from the 1034/947 children at baseline/follow-up were aggregated (approximately ten children per school at each time point). School-level weighted regression models were constructed (i.e. each school formed a single unit of analyses, with models weighted to adjust for variability in the number of pupils sampled within each school) adjusting for baseline score and the four stratification variables. All models examine post-intervention follow-up data as the dependent variable. As is standard practice in testing moderation of intervention effects by $\mathrm{SES}^{(50)}$, models are presented in two stages: first, containing variables for intervention status and FSM entitlement without an interaction term; and second, with an FSM $\times$ intervention status interaction term added.

Percentage FSM entitlement was converted to proportions, so that $b$ coefficients reflect change in the dependent variable if all children within a school are entitled to FSM $v$. none. Separate models were run for each of two markers of deprivation (e.g. proportion FSM entitlement among the whole school or among study participants). The first set of models, using school-level FSM percentages, replicates and extends analyses published in the main trial outcomes paper ${ }^{(39)}$. The second set of models replicates these models, but uses aggregated values from data on the FSM entitlement of individual children (linked to trial data via the SAIL databank), providing a more precise estimate of the socio-economic composition of the specific groups of 9-11-year-old children participating in the study. Analyses were conducted on an intention-totreat basis, with 'intervention status' representing the treatment condition to which the school had been randomised (control, $n 56$; intervention, $n 55$ ). However, no individual-level FSM data were available for three schools (all of which were intervention schools), with models using these data including 108 schools (control, $n$ 56; intervention, $n$ 52).

Finally, individual-level analyses examined differences in key outcomes between children in intervention and control schools who completed measures at follow-up ( $n$ 3068), with models including the same control variables entered into aggregate-level analysis, including school-level mean baseline scores for the dependent variable. Linear regression was used for normally distributed variables, with highly skewed or categorical variables divided into tertiles and subjected to ordinal logistic regression. Test of parallel lines statistics in SPSS indicated no violation of proportional odds assumptions. Models were adjusted for clustering at the school level using the complex samples module in the statistical software package IBM SPSS Statistics 18. In discussion of findings, a $P$ value of 0.05 or less is considered statistically significant.

\section{Results}

\section{Deprivation}

The percentage of children in each school entitled to FSM ranged from $3 \cdot 1 \%$ to $65.9 \%$ with the mean $(26 \cdot 1 \%$; SD $13.5 \% ; n 111$ ) higher than the national average of $17 \%$. The percentage of study participants within each school entitled to FSM ranged from 0 to $61 \cdot 0 \%$ (mean $22 \cdot 8 \%$; SD $13 \cdot 2 \% ; n$ 108). The two deprivation markers were highly correlated $(r=0 \cdot 82)$, indicating that the socio-economic composition of classes selected for testing within each school was similar to that of the school as a whole. 
Table 1 Baseline characteristics of stratification variables by randomisation status: cluster-randomised controlled trial examining the impact of the Primary School Free Breakfast Initiative in Wales on inequalities in children's dietary behaviours and cognitive functioning

\begin{tabular}{|c|c|c|c|c|}
\hline Variable & \multicolumn{2}{|c|}{ Control $(n 56)$} & \multicolumn{2}{|c|}{ Intervention ( $n$ 55) } \\
\hline \multicolumn{5}{|l|}{ School size } \\
\hline Mean & \multicolumn{2}{|c|}{$189 \cdot 18$} & \multicolumn{2}{|c|}{$197 \cdot 93$} \\
\hline SD & \multicolumn{2}{|c|}{$96 \cdot 14$} & \multicolumn{2}{|c|}{$92 \cdot 68$} \\
\hline Min & \multicolumn{2}{|c|}{23} & & \\
\hline $\operatorname{Max}$ & & & \multicolumn{2}{|c|}{540} \\
\hline & $n$ & $\%$ & $n$ & $\%$ \\
\hline \multicolumn{5}{|l|}{ Language of teaching } \\
\hline English or bilingual & 52 & 93 & 51 & 93 \\
\hline Welsh & 4 & 7 & 4 & 7 \\
\hline \multicolumn{5}{|l|}{ Local education authority } \\
\hline LEA1 & 3 & 5 & 2 & 4 \\
\hline LEA2 & 5 & 9 & 6 & 11 \\
\hline LEA3 & 5 & 9 & 5 & 9 \\
\hline LEA4 & 10 & 18 & 9 & 16 \\
\hline LEA5 & 7 & 13 & 10 & 18 \\
\hline LEA6 & 4 & 7 & 4 & 7 \\
\hline LEA7 & 6 & 11 & 6 & 11 \\
\hline LEA8 & 13 & 23 & 10 & 18 \\
\hline LEA9 & 3 & 5 & 3 & 6 \\
\hline \multicolumn{5}{|c|}{ Community First area (socio-economically deprived) } \\
\hline Non-Community First & 27 & 48 & 26 & 47 \\
\hline Community First & 29 & 52 & 29 & 53 \\
\hline
\end{tabular}

Table 2 Post-intervention school-level mean values (and standard deviations) for outcome variables of interest (baseline values are reported in Murphy et al. ${ }^{(39)}$ ): cluster-randomised controlled trial examining the impact of the Primary School Free Breakfast Initiative in Wales on inequalities in children's dietary behaviours and cognitive functioning

\begin{tabular}{lrrrrrr}
\hline & \multicolumn{2}{c}{ Control } & & \multicolumn{2}{c}{ Intervention } \\
\cline { 2 - 3 } & Mean & SD & & Mean & SD \\
\hline Healthy items for breakfast & 3.45 & 0.48 & & 3.73 & 0.58 \\
Unhealthy items for breakfast & 0.23 & 0.16 & & 0.23 & 0.13 \\
Rest-of-day fruit and vegetables & 1.00 & 0.42 & & 0.88 & 0.30 \\
Rest-of-day unhealthy items & 1.19 & 0.33 & & 1.10 & 0.30 \\
Attitudes & 36.63 & 2.57 & & $37 \cdot 23$ & 2.05 \\
Episodic memory & 5.72 & 0.76 & & $5 \cdot 76$ & 0.60 \\
Hyperactivity & 3.01 & 1.27 & & 3.25 & 1.01 \\
\hline
\end{tabular}

Baseline characteristics of intervention and control schools are presented in Table 1.

\section{Dietary bebaviour and attitudes towards breakfast}

Mean and standard deviation of post-intervention scores for key variables are presented in Table 2 . As indicated in Table 3 , children in schools randomised to receive the PSFBI consumed significantly more healthy items at breakfast and had more positive attitudes towards breakfast than children in control schools in school-level analyses. The $b$ coefficient indicates the difference between groups in the average number of healthy items consumed; hence the $b$ coefficient of 0.25 indicated that, on average, pupils in intervention schools ate 0.25 more servings of healthy items than did those in control schools. In individual-level analyses however, intervention effects were smaller, with differences significant only in relation to consumption of healthy items for breakfast and unhealthy items throughout the remainder of the day. Differences between intervention and control groups in relation to all other dietary behaviours were non-significant.

When the measure of deprivation was the overall percentage of children in the school entitled to FSM, a higher level of deprivation was associated with decreased consumption of unhealthy items during the rest of the day and poorer attitudes towards breakfast. Positive associations between deprivation and breakfast skipping, and between deprivation and consumption of unhealthy items at breakfast, became significant only after entry of an FSM $\times$ randomisation interaction term. A negative association of deprivation and fruit and vegetable consumption also became significant. Conversely, an association of deprivation with consumption of unhealthy items during the rest of the day became nonsignificant on entry of the interaction term. Findings were similar when the percentage of study participants within the school entitled to FSM was used as the marker of deprivation, although a significant association of deprivation and consumption of fruit and vegetables during the remainder of the day was observed both before and after entry of an interaction term. In individual-level analyses, household deprivation was significantly associated with increased consumption of unhealthy items for breakfast, increased breakfast skipping, poorer attitudes towards breakfast, consumption of fewer fruit and vegetables throughout the rest of the day, as well as consumption of fewer unhealthy items throughout the rest of the day. Only the consumption of healthy items for breakfast was not significantly associated with household deprivation.

In school-level analyses, significant interactions were observed between intervention status and deprivation in relation to both consumption of healthy items at breakfast and breakfast skipping, although only the association with breakfast skipping was significant in individuallevel analysis. Hence, school-level analysis (though not individual-level analysis) indicated that the number of healthier items eaten at breakfast differed across trial arms to a greater extent in more deprived schools than in less deprived schools, while despite no aggregate differences between trial arms in terms of breakfast skipping, significantly greater differences between trial arms were observed in more deprived schools.

\section{Episodic memory}

There were no intervention effects upon episodic memory. Episodic memory was significantly poorer in children in receipt of FSM in individual-level analysis, although no association was observed in analysis using school-level FSM entitlement. No interaction between deprivation and intervention status was observed. 
Table $3 b$ coefficients or odds ratios and $95 \%$ confidence intervals for associations of the Primary School Free Breakfast Initiative and deprivation with 12 -month dietary and cognitive outcomes (model 1) and interactions with deprivation (model 2)

\begin{tabular}{|c|c|c|c|c|c|c|}
\hline & \multicolumn{2}{|c|}{$\begin{array}{l}\text { School-level models ( } n \text { 111) with \% FSM } \\
\text { among whole school as deprivation marker }\end{array}$} & \multicolumn{2}{|c|}{$\begin{array}{l}\text { School-level models ( } n \text { 108) with \% FSM among } \\
\text { study participants as deprivation marker }\end{array}$} & \multicolumn{2}{|c|}{$\begin{array}{l}\text { Individual-level models adjusted for } \\
\text { aggregated baseline values }\end{array}$} \\
\hline & $b$ or OR & $95 \% \mathrm{Cl}$ & $b$ or OR & $95 \% \mathrm{Cl}$ & $b$ or OR & $95 \% \mathrm{Cl}$ \\
\hline Healthy items at breakfast & & & & & \multicolumn{2}{|c|}{$n 3068$} \\
\hline Model 1 & & & & & & \\
\hline Intervention & 0.25 & $0 \cdot 07,0 \cdot 44^{\star \star \star}$ & 0.23 & $0.05,0.42^{\star *}$ & $0 \cdot 16$ & $0 \cdot 02,0 \cdot 30^{\star *}$ \\
\hline Deprivation & -0.03 & $-0.89,0.84$ & $0 \cdot 16$ & $-0.69,1.01$ & 0.07 & $-0.08,0.22$ \\
\hline \multicolumn{7}{|l|}{ Model 2} \\
\hline Intervention & 0.25 & $0.08,0.43^{\star \star \star}$ & 0.23 & $0.05,0.41^{\star \star \star}$ & $0 \cdot 11$ & $-0.05,0.27$ \\
\hline Deprivation & -0.69 & $-1 \cdot 69,0 \cdot 30$ & -0.56 & $-1 \cdot 58,0 \cdot 47$ & -0.02 & $-0 \cdot 21,0 \cdot 17$ \\
\hline Interaction term & $1 \cdot 76$ & $0 \cdot 36,3 \cdot 16^{\star \star}$ & $1 \cdot 75$ & $0 \cdot 29,3 \cdot 22^{\star \star}$ & $0 \cdot 18$ & $-0.11,0.48$ \\
\hline Unhealthy items at breakfast & & & & & \multicolumn{2}{|c|}{$n 3068 \ddagger$} \\
\hline Model 1 & & & & & & \\
\hline Intervention & 0.00 & $-0.05,0.05$ & 0.02 & $-0.04,0.07$ & 1.05 & $0 \cdot 86,1 \cdot 29$ \\
\hline Deprivation & $0 \cdot 22$ & $-0.03,0.46^{*}$ & $0 \cdot 21$ & $-0.03,0.45^{\star}$ & 1.35 & $1 \cdot 06,1 \cdot 73^{\star \star}$ \\
\hline \multicolumn{7}{|l|}{ Model 2} \\
\hline Intervention & 0.00 & $-0.05,0.05$ & 0.02 & $-0.04,0.07$ & 1.05 & $0 \cdot 84,1 \cdot 31$ \\
\hline Deprivation & $0 \cdot 43$ & $0 \cdot 10,0 \cdot 75^{\star \star}$ & $0 \cdot 31$ & $-0.03,0.64^{\star}$ & $1 \cdot 34$ & $1 \cdot 01,1 \cdot 76^{\star \star}$ \\
\hline Interaction term & -0.37 & $-0.75,0.01^{*}$ & $-0 \cdot 17$ & $-0.58,0.23$ & 1.03 & $0.63,1.45$ \\
\hline Fruit and vegetables during the rest of the day & & & & & \multicolumn{2}{|c|}{$n 3068 \ddagger$} \\
\hline Model 1 & & & & & & \\
\hline Intervention & -0.02 & $-0.04,0.01$ & -0.02 & $-0.04,0.01$ & 0.89 & $0.76,1.05$ \\
\hline Deprivation & -0.07 & $-0.20,0.04$ & $-0 \cdot 14$ & $-0.26,-0.02^{\star *}$ & 0.75 & $0.63,0.89^{* \star *}$ \\
\hline \multicolumn{7}{|l|}{ Model 2} \\
\hline Intervention & -0.02 & $-0.04,0.01$ & -0.02 & $-0.05,0.01$ & 0.88 & $0.74,1.06$ \\
\hline Deprivation & $-0 \cdot 18$ & $-0.35,-0.01^{* *}$ & -0.25 & $-0.42,-0.08^{\star * *}$ & $0 \cdot 74$ & $0.59,0.92^{\star * *}$ \\
\hline Interaction term & 0.17 & $-0 \cdot 02,0.37^{\star}$ & 0.19 & $-0.01,0.39^{\star}$ & \multirow{2}{*}{\multicolumn{2}{|c|}{$1.03 \quad n 3068 \ddagger$}} \\
\hline Unhealthy items during the rest of the day & & & & & & \\
\hline Model 1 & & & & & & \\
\hline Intervention & -0.01 & $-0.03,0.01$ & -0.01 & $-0.04,0.01$ & 0.81 & $0.69,0.95^{\star \star *}$ \\
\hline Deprivation & $-0 \cdot 12$ & $-0.21,-0.03^{\star \star}$ & -0.07 & $-0.16,0.03$ & 0.66 & $0.56,0.78^{\star \star \star}$ \\
\hline \multicolumn{7}{|l|}{ Model 2} \\
\hline Intervention & -0.01 & $-0.03,0.01$ & -0.01 & $-0.04,0.01$ & 0.82 & $0.67,0.99^{\star \star}$ \\
\hline Deprivation & $-0 \cdot 10$ & $-0 \cdot 22,0 \cdot 01^{*}$ & -0.07 & $-0.19,0.05$ & 0.67 & $0.54,0.84^{* \star *}$ \\
\hline Interaction term & -0.04 & $-0 \cdot 19,0 \cdot 11$ & 0.01 & $-0 \cdot 15,0 \cdot 17$ & 0.96 & $0 \cdot 69,1 \cdot 35$ \\
\hline Breakfast skipping & & & & & \multicolumn{2}{|c|}{$n 3068 \ddagger$} \\
\hline Model 1 & & & & & & \\
\hline Intervention & 0.00 & $-0.01,0.01$ & 0.00 & $-0.01,0.01$ & 0.96 & $0 \cdot 79,1 \cdot 15$ \\
\hline Deprivation & 0.02 & $-0.02,0.07$ & 0.03 & $-0.01,0.08$ & $1 \cdot 22$ & $1 \cdot 00,1 \cdot 50^{\star \star}$ \\
\hline \multicolumn{7}{|l|}{ Model 2} \\
\hline Intervention & -0.00 & $-0.01,0.01$ & 0.00 & $-0.01,0.01$ & 1.06 & $0.85,1.32$ \\
\hline Deprivation & 0.06 & $0 \cdot 00,0 \cdot 11^{\star *}$ & 0.06 & $0.01,0 \cdot 12^{\star *}$ & $1 \cdot 48$ & $1 \cdot 14,1 \cdot 92^{\star \star *}$ \\
\hline Interaction term & -0.07 & $-0 \cdot 15,-0.00^{\star \star}$ & -0.07 & $-0 \cdot 15,0.01^{*}$ & 0.67 & $0.46,0.98^{\star \star}$ \\
\hline
\end{tabular}




\begin{tabular}{|c|c|c|c|c|c|c|}
\hline & \multicolumn{2}{|c|}{$\begin{array}{l}\text { School-level models ( } n \text { 111) with \% FSM } \\
\text { among whole school as deprivation marker }\end{array}$} & \multicolumn{2}{|c|}{$\begin{array}{l}\text { School-level models ( } n \text { 108) with \% FSM among } \\
\text { study participants as deprivation marker }\end{array}$} & \multicolumn{2}{|c|}{$\begin{array}{l}\text { Individual-level models adjusted for } \\
\text { aggregated baseline values }\end{array}$} \\
\hline & $b$ or OR & $95 \% \mathrm{Cl}$ & $b$ or OR & $95 \% \mathrm{Cl}$ & $b$ or OR & $95 \% \mathrm{Cl}$ \\
\hline Attitudes towards breakfast & & & & & \multicolumn{2}{|c|}{$n 3016$} \\
\hline Intervention & 0.85 & $0 \cdot 20,1 \cdot 50^{\star *}$ & 0.63 & $-0.02,1 \cdot 27^{\star}$ & 0.37 & $-0.23,0.97$ \\
\hline Deprivation & $-5 \cdot 97$ & $-9 \cdot 13,-2 \cdot 82^{\star \star \star}$ & $-6 \cdot 32$ & $-9 \cdot 30,-3 \cdot 33^{\star \star *}$ & $-1 \cdot 63$ & $-2 \cdot 41,-0 \cdot 84^{\star \star \star}$ \\
\hline \multicolumn{7}{|l|}{ Model 2} \\
\hline Intervention & 0.85 & $0 \cdot 20,1 \cdot 50^{\star *}$ & 0.62 & $-0.02,1 \cdot 26^{\star}$ & $0 \cdot 18$ & $-0.47,0.83$ \\
\hline Deprivation & $-7 \cdot 70$ & $-11 \cdot 83,-3 \cdot 56^{\star \star \star}$ & -8.08 & $-12 \cdot 08,-4 \cdot 08^{\star \star \star}$ & $-2 \cdot 03$ & $-3.08,-0.98^{\star \star \star}$ \\
\hline Interaction term & $3 \cdot 18$ & $-1 \cdot 76,8 \cdot 12$ & $3 \cdot 28$ & $-1 \cdot 68,8 \cdot 24$ & $0 \cdot 84$ & $-0 \cdot 71,2 \cdot 38$ \\
\hline Episodic memory (group) & & & & & \multicolumn{2}{|c|}{$n 2970$} \\
\hline Model 1 & & & & & & \\
\hline Intervention & 0.06 & $-0 \cdot 19,0 \cdot 31$ & 0.03 & $-0 \cdot 23,0 \cdot 28$ & -0.01 & $-0.25,0.24$ \\
\hline Deprivation & -0.95 & $-2 \cdot 13,0 \cdot 24$ & $-1 \cdot 28$ & $-2 \cdot 47,-0 \cdot 09^{\star \star}$ & -0.95 & $-1 \cdot 19,-0 \cdot 72^{\star \star \star}$ \\
\hline \multicolumn{7}{|l|}{ Model 2} \\
\hline Intervention & 0.06 & $-0.19,0.31$ & 0.03 & $-0.23,0.29$ & -0.07 & $-0.37,0.23$ \\
\hline Deprivation & -0.08 & $-1 \cdot 63,1 \cdot 46$ & -0.93 & $-2 \cdot 55,0.69$ & $-1 \cdot 08$ & $-1 \cdot 42,-0 \cdot 74^{\star \star \star}$ \\
\hline Interaction term & -1.62 & $-3 \cdot 49,0.26$ & -0.63 & $-2 \cdot 61,1 \cdot 36$ & $0 \cdot 26$ & $-0.23,0.75$ \\
\hline Hyperactivity ${ }^{+}$ & & & & & \multicolumn{2}{|c|}{$n 686 \ddagger$} \\
\hline Model 1 & & & & & & \\
\hline Intervention & $0 \cdot 18$ & $-0.30,0.66$ & 0.18 & $-0.30,0.66$ & $1 \cdot 17$ & $0.84,1 \cdot 63$ \\
\hline Deprivation & -0.09 & $-2 \cdot 39,2 \cdot 21$ & -0.56 & $-0 \cdot 79,1 \cdot 25$ & $1 \cdot 76$ & $1 \cdot 27,2 \cdot 44^{\star \star \star}$ \\
\hline \multicolumn{7}{|l|}{ Model 2} \\
\hline Intervention & $0 \cdot 17$ & $-0.32,0.65$ & $0 \cdot 18$ & $-0.30,0.67$ & 1.03 & $0 \cdot 71,1 \cdot 14$ \\
\hline Deprivation & 0.48 & $-2 \cdot 83,3 \cdot 78$ & $-0 \cdot 70$ & $-3.96,2.55$ & 1.36 & $0.91,2.02$ \\
\hline Interaction term & $-0 \cdot 88$ & $-4 \cdot 53,2 \cdot 77$ & 0.23 & $-3 \cdot 43,3 \cdot 89$ & $1 \cdot 74$ & $0.94,3.20$ \\
\hline
\end{tabular}

FSM, free school meals.

Statistically significant: ${ }^{\star} P<0 \cdot 1,{ }^{* \star} P<0 \cdot 05,{ }^{* \star *} P<0 \cdot 01$

tData collected from a sub-sample in each of 105/99 schools at baseline/follow-up.

$\ddagger$ Odds ratios from ordinal logistic regression models. 


\section{Bebavioural outcomes}

No significant associations were found between intervention status, deprivation or the interaction term in terms of hyperactivity, apart from a significant association between FSM entitlement and hyperactivity in individuallevel analyses.

\section{Discussion}

The present study aimed to examine the impact of universal breakfast provision on socio-economic inequalities in children's dietary behaviours and cognitive functioning. When assessed at the school level, deprivation was associated with poorer attitudes towards breakfast, higher levels of breakfast skipping and consumption of unhealthy breakfast items and consumption of fewer fruits and vegetables in final models. However, in contrast to associations apparent in the baseline data ${ }^{(20)}$, consumption of 'healthy' items for breakfast was no longer associated with school-level deprivation at follow-up. Deprivation appeared to be a stronger and more consistent predictor of adverse outcomes when assessed at the household level rather than the school level. At the household level (i.e. individual-level FSM entitlement), deprivation was associated with consumption of a significantly higher number of unhealthy breakfast items, consumption of fewer fruits and vegetables, a higher risk of breakfast skipping, poorer attitudes towards breakfast, poorer episodic memory and higher levels of hyperactivity. Only consumption of healthy items for breakfast was not associated with deprivation, while counter to the dominant trend for poorer health behaviours among more deprived children, children entitled to FSM also reported eating fewer unhealthy items throughout the day following breakfast. This may reflect the greater likelihood of such children to have a school meal rather than a packed lunch, and hence fewer snacks. It should however be noted that at baseline, children from poorer schools were shown to under-report consumption of more unhealthy food items to a greater extent than those from more affluent schools, with this trend perhaps therefore an artifact of biased reporting ${ }^{(51)}$.

In relation to some dietary behaviours, there was evidence that universal breakfast provision disproportionately benefited children from lower-SES schools and families. For the consumption of healthy items for breakfast, schoollevel models indicated larger differences between control and intervention groups among children from more deprived schools, with this narrowing of inequality perhaps accounting for the lack of significant association between deprivation and consumption of healthy breakfast items in follow-up data. In individual-level analysis however, this interaction was not significant. Notably, despite the fact that aggregate-level analyses indicated that breakfast skipping was not significantly reduced by the intervention $^{(39)}$, a significant interaction was observed between intervention status and breakfast skipping, indicating that breakfast skipping was reduced among children from more deprived schools and households. Further interactions indicating decreased consumption of unhealthy breakfast items at breakfast, and increased fruit and vegetable consumption throughout the rest of the day, among children from poorer schools were significant at the $10 \%$ level. Importantly, there was no evidence in relation to any measured outcomes of worsening of inequalities. Hence, the study provides support for the notion that universal interventions which involve changing the environment in order to facilitate healthier behaviours may be more likely to reduce inequalities than to make them worse ${ }^{(1)}$.

A number of strengths and limitations of the study merit consideration before considering its implications. It benefits from a large sample of schoolchildren from Wales and the use of pre-validated measures, or measures validated for the purpose of the study. Nevertheless, while validated, the study relies upon self-report measures, likely subject to social desirability biases. Furthermore, it was not possible to link all participating children to data on individual-level FSM entitlement, potentially introducing error to estimates of the percentage of children in participating classes entitled to FSM.

Nevertheless, while in some settings breakfast provision continues to be targeted towards areas of deprivation, the present paper provides important evidence that universal provision of free school breakfasts can disproportionately benefit children from poorer backgrounds, in terms of discouraging breakfast skipping and increasing the consumption of healthier breakfast items. For no outcome was there evidence that universal breakfast provision disproportionately benefited children from more affluent backgrounds. Hence, offering breakfast provision on a universal rather than targeted basis may play a significant role in reducing inequalities in health and is unlikely to widen them. This avoids the stigmatisation of individuals, schools, families or communities, which may occur when labelling them as needy ${ }^{(33)}$, and may play a greater role in reducing social gradients in health outcomes. In addition, given that relationships between SES and health outcomes are typically graded rather than dichotomous, targeting the very poorest will do little to address inequalities throughout the distribution ${ }^{(34)}$. On a broader level, the study supports assertions that universal interventions can play an important role in reducing inequalities ${ }^{(1)}$ and that interventions targeting higher-level environmental factors in order to facilitate healthier behaviours, rather than focusing upon influencing individual choice through education and information provision, may be more likely to reduce inequalities $^{(35-38)}$. It demonstrates the importance of heeding Whitehead's calls for interventions which aim to promote population-level change to be evaluated not only in terms of aggregate effectiveness, but also in terms of impact on inequalities ${ }^{(37)}$. 


\section{Acknowledgements}

Sources of funding: The work was funded via the National Prevention Research Initiative http://www.npri.org.uk (grant number 87122). Funding from the British Heart Foundation, Cancer Research UK, the Department of Health, Diabetes UK, the Economic and Social Research Council, the Medical Research Council, the Research and Development Office for the Northern Ireland Health and Social Services, the Chief Scientist Office, the Scottish Executive Health Department, The Stroke Association, the Welsh Assembly Government and the World Cancer Research Fund is gratefully acknowledged. The work was undertaken with the support of The Centre for the Development and Evaluation of Complex Interventions for Public Health Improvement (DECIPHer), a UKCRC Public Health Research: Centre of Excellence. Funding from the British Heart Foundation, Cancer Research UK, the Economic and Social Research Council (RES-590-28-0005), the Medical Research Council, the Welsh Government and the Wellcome Trust (WT087640MA), under the auspices of the UK Clinical Research Collaboration, is gratefully acknowledged. The funders played no role in the design, analysis or writing of this article. Conflicts of interest: The authors have no conflicts of interest to declare. Ethics: The study received ethical approval from the Cardiff University School of Social Sciences Research Ethics Committee. Authors' contributions: G.F.M. drafted the manuscript. G.F.M. and K.C. conducted analysis. M.A. contributed to the linkage of trial and routine data, managed by R.A.L. All authors commented on drafts and approved the final manuscript. Acknowledgements: The authors are grateful to Chris Roberts and Janine Hale within the Welsh Government's Health Improvement Division for supporting the original trial and data linkage.

\section{References}

1. Marmot MG, Allen J, Goldblatt P et al. (2010) Fair Society, Healthy Lives. Strategic Review of Health Inequalities in England post-2010. London: The Marmot Review; available at http://www.instituteofhealthequity.org/Content/ FileManager/pdf/fairsocietyhealthylives.pdf

2. Marmot M (2005) Social determinants of health inequalities. Lancet 365, 1099-1104.

3. Law C, Power C, Graham H et al. (2007) Obesity and health inequalities. Obes Rev 8, 19-22.

4. Stringhini S, Sabia S, Shipley M et al. (2010) Association of socioeconomic position with health behaviors and mortality. JAMA 303, 1159-1166.

5. Hanson MD \& Chen E (2007) Socioeconomic status and health behaviors in adolescence: a review of the literature. J Behav Med 30, 263-285.

6. Inman DD, van Bakergem KM, LaRosa AC et al. (2011) Evidence-based health promotion programs for schools and communities. Am J Prev Med 40, 207-219.

7. Bruno-Ambrosius K, Swanholm G \& Twetman S (2005) Eating habits, smoking and toothbrushing in relation to dental caries: a 3-year study in Swedish female teenagers. Int J Paediatr Dent 15, 190-196.

8. Fujiwara T (2003) Skipping breakfast is associated with dysmenorrhea in young women in Japan. Int J Food Sci Nutr 54, 505-509.

9. Berkey CS, Rockett HRH, Gillman MW et al. (2003) Longitudinal study of skipping breakfast and weight change in adolescents. Int J Obes Relat Metab Disord 27, $1258-1266$.

10. Nicklas TA, Bao W, Webber LS et al. (1993) Breakfast consumption affects adequacy of total daily intake in children. J Am Diet Assoc 93, 886-891.

11. Sjoberg A, Hallberg L, Hoglund D et al. (2003) Meal pattern, food choice, nutrient intake and lifestyle factors in The Goteborg Adolescence Study. Eur J Clin Nutr 57, 1569-1578.

12. Williams BM, O'Neil CE, Keast DR et al. (2009) Are breakfast consumption patterns associated with weight status and nutrient adequacy in African-American children? Public Health Nutr 12, 489-496.

13. Smith AP, Clark R \& Gallagher J (1999) Breakfast cereal and caffeinated coffee: effects on working memory, attention, mood and cardiovascular function. Physiol Behav 67, 9-17.

14. Smith AP, Kendrick A, Maben A et al. (1994) Effects of breakfast and caffeine on cognitive performance mood and cardiovascular functioning. Appetite 22, 39-55.

15. Smith AP, Kendrick AM \& Maben AL (1993) Effects of breakfast and caffeine on performance and mood in the late morning and after lunch. Neuropsychobiology 26, 198-204

16. Benton D \& Parker PY (1998) Breakfast, blood glucose, and cognition. Am J Clin Nutr 67, issue 4, 772S-778S.

17. Benton D \& Sargent J (1992) Breakfast, blood-glucose and memory. Biol Psychol 33, 207-210.

18. Corder K, van Sluijs EMF, Steele RM et al. (2011) Breakfast consumption and physical activity in British adolescents. $\mathrm{Br}$ J Nutr 105, 316-321.

19. Hoyland A, McWilliams KA, Duff RJ et al. (2012) Breakfast consumption in UK schoolchildren and provision of school breakfast clubs. Nutr Bull 37, 232-240.

20. Moore GF, Tapper K, Murphy S et al. (2007) Associations between deprivation, attitudes towards eating breakfast and breakfast eating behaviours in 9-11-year-olds. Public Health Nutr 10, 582-589.

21. Friedman BJ \& Hurd-Crixell SL (1999) Nutrient intake of children eating school breakfast. J Am Diet Assoc 99, 219-221.

22. US Department of Agriculture (1999) Time for School Breakfast: Healthy Eating Helps You Make the Grade. Washington, DC: USDA.

23. Moore L, Moore GF, Tapper K et al. (2007) Free breakfasts in schools: design and conduct of a cluster randomised controlled trial of the Primary School Free Breakfast Initiative in Wales [ISRCTN18336527]. BMC Public Health 7, 258.

24. Thomas M (2012) Free school breakfasts in Wales. The Guardian, 20 June 2012; available at http://www. theguardian.com/teacher-network/teacher-blog/2012/jun/20/ free-school-breakfasts-wales

25. Belderson P, Brandon M, Camina M et al. (2001) A National Evaluation of School Breakfast Clubs. Final Report. Norwich: University of East Anglia.

26. Bro RT, Shank L, Williams R et al. (1994) The effects of an in-class breakfast program on attendance and on-task behaviour of high school students. Child Fam Behav Ther 16, 1-8.

27. Hanes S, Vermeersch J \& Gale S (1984) The national evaluation of school nutrition programs: program impacts on dietary intake. Am J Clin Nutr 40, 390-413.

28. Murphy JM, Pagano ME, Nachmani J et al. (1998) The relationship of school breakfast to psychosocial and 
academic functioning. Arch Pediatr Adolesc Med 152, 899-907.

29. Pollitt E (1995) Does breakfast make a difference in school? J Am Diet Assoc 95, 1134-1139.

30. Shemilt I, Harvey I, Shepstone L et al. (2004) A national evaluation of school breakfast clubs: evidence from a cluster randomized controlled trial and an observational analysis. Child Care Health Dev 30, 413-427.

31. Shemilt I, O'Brien M, Thoburn J et al. (2003) School breakfast clubs, children and family support. Children $\varepsilon$ Society 17, 111-112.

32. Crepinsek MK, Singh A, Bernstein LS et al. (2006) Dietary effects of universal-free school breakfast: findings from the evaluation of the School Breakfast Program Pilot Project. J Am Diet Assoc 106, 1796-1803.

33. Mhurchu CN, Gorton D, Turley M et al. (2012) Effects of a free school breakfast programme on children's attendance, academic achievement and short-term hunger: results from a stepped-wedge, cluster randomised controlled trial. J Epidemiol Community Health 67, 257-264.

34. Harper C \& Wood L (2009) Please Sir? Can We Have Some More? - Lessons from Free School Meal Initiatives. Sheffield: School Food Trust.

35. Whitehead M (2007) A typology of actions to tackle social inequalities in health. J Epidemiol Community Health 61, 473-478.

36. Phelan JC, Link BG \& Tehranifar P (2010) Social conditions as fundamental causes of health inequalities theory, evidence, and policy implications. J Health Soc Behav $\mathbf{5 1}$, 1 Suppl., S28-S40.

37. White M, Adams J \& Heywood P (2009) How and why do interventions that increase health overall widen inequalities within populations? In Health, Inequality and Society, pp. 65-82 [S Babones, editor]. Bristol: Policy Press.

38. Lorenc T, Petticrew M, Welch V et al. (2012) What types of interventions generate inequalities? Evidence from systematic reviews. J Epidemiol Community Health 67, 190-193.

39. Murphy S, Moore GF, Tapper K et al. (2011) Free healthy breakfasts in primary schools: a cluster randomised controlled trial of a policy intervention in Wales. Public Health Nutr 14, 219-226.
40. Welsh Assembly Government (2006) Free Breakfast Initiative. http://new.wales.gov.uk/topics/educationandskills/ schoolshome/foodanddrink/breakfast/?lang=en （accessed August 2013).

41. Tapper K, Murphy S, Lynch R et al. (2007) Development of a scale to measure 9-11-year-olds' attitudes towards breakfast. Eur J Clin Nutr 62, 511-518.

42. Edmunds LD \& Ziebland S (2002) Development and validation of the Day in the Life Questionnaire (DILQ) as a measure of fruit and vegetable questionnaire for 7-9 year olds. Health Educ Res 17, 211-220.

43. Moore GF, Tapper K, Murphy S et al. (2006) Validation of a self-completion measure of breakfast foods, snacks and fruits and vegetables consumed by 9- to 11-year-old schoolchildren. Eur J Clin Nutr 61, 420-430.

44. Smith A, Kendrick A, Maben A et al. (1994) Effects of breakfast and caffeine on cognitive performance, mood and cardiovascular functioning. Appetite 22, 39-55.

45. Smith AP, Clark R \& Gallagher J (1999) Breakfast cereal and caffeinated coffee: effects on working memory, attention, mood, and cardiovascular function. Physiol Behav 67, 9-17.

46. Smith AP \& Miles C (1986) Effects of lunch on selective and sustained attention. Neuropsychobiology 16, 117-120.

47. Goodman R (2001) Psychometric properties of the strengths and difficulties questionnaire. J Am Acad Child Adolesc Psychol 40, 1337-1345.

48. Lyons R, Jones K, John G et al. (2009) The SAIL databank: linking multiple health and social care datasets. BMC Med Inform Decis Mak 9, 3.

49. Ford D, Jones K, Verplancke J-P et al. (2009) The SAIL databank: building a national architecture for e-health research and evaluation. BMC Health Serv Res 9, 157.

50. Moore GF, Currie D, Gilmore G et al. (2012) Socioeconomic inequalities in childhood exposure to secondhand smoke before and after smoke-free legislation in three UK countries. Public Health 34, 599-608.

51. Moore GF, Tapper K, Moore L et al. (2008) Cognitive, behavioral, and social factors are associated with bias in dietary questionnaire self-reports by schoolchildren aged 9 to 11 years. J Am Diet Assoc 108, 1865-1873. 